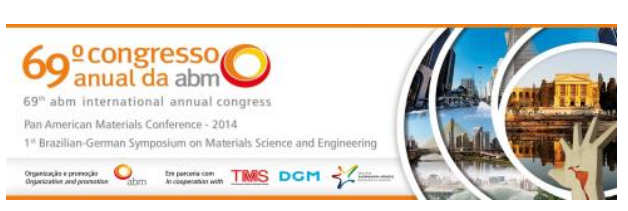

Tema: Iniciação Científico-Tecnológica

\title{
INFLUÊNCIA DA TEMPERATURA NO COMPORTAMENTO À CORROSÃO E À CORROSÃO SOB TENSÃO DO AÇO INOXIDÁVEL DÚPLEX AISI 318 EM MEIO CONTENDO CLORETO*
}

\section{Resumo}

\author{
Leandro Brunholi Ramos ${ }^{1}$ \\ Maiquel Antoniazi da Rosa ${ }^{2}$ \\ Cristiane de Souza Brandolt ${ }^{3}$ \\ Roberto Moreira Schroede ${ }^{4}$ \\ Iduvirges Lourdes Müller ${ }^{5}$
}

Foi estudado o efeito da temperatura no comportamento à corrosão sob tensão do aço inoxidável dúplex AISI 318 em solução contendo 115.000 ppm de cloreto, pH4 a temperatura ambiente e a $70^{\circ} \mathrm{C}$. Ensaios de tração com baixa de taxa de deformação foram realizados. Foi avaliada a susceptibilidade do aço inoxidável dúplex AISI 318 à corrosão sob tensão no potencial de circuito aberto e em vários potenciais anódicos e catódicos. Os resultados mostraram que a redução do alongamento variou com o potencial aplicado. Os resultados experimentais mostraram que o aço AISI 318 ficou imune à corrosão sob tensão em potencial entre -750 mVECS e 1.000 mVECS na temperatura ambiente e entre -650 e -100mVECS para a temperatura de $70^{\circ} \mathrm{C}$. Em potenciais maiores que o potencial de pite observou-se uma redução drástica no alongamento em ambas as temperaturas. No entanto, quando os potenciais aplicados foram abaixo de $-650 \mathrm{mV}$ ECs para a temperatura de $70^{\circ} \mathrm{C}$ e $-750 \mathrm{mV}$ ECS para a temperatura ambiente, houve uma redução no alongamento final até a ruptura, provavelmente através do processo de fragilização por hidrogênio.

Palavras-chave: Aço inoxidável dúplex; Corrosão sob tensão; Ensaio de tração com baixa taxa de deformação.

\section{INFLUENCE OF TEMPERATURE ON STRESS CORROSION CRACKING BEHAVIOUR OF DÚPLEX STAINLESS STEEL AISI 318 IN SOLUTION CONTAINING CHLORIDE \\ Abstract}

The effect of temperature on the stress corrosion cracking behavior of an AISI 318 dúplex stainless steel in a $115,000 \mathrm{ppm}$ chloride ions solution with $\mathrm{pH} 4$ at room temperature or $70^{\circ} \mathrm{C}$ was investigated. Slow strain rate testing was performed. The susceptibility of an AISI 318 dúplex stainless steel to stress corrosion cracking at open circuit potential and at various anodic and cathodic potentials was evaluated. The results showed that the reduction in the elongation varied with the applied potential. The experimental results showed that AISI 318 was immune to stress corrosion cracking in potentials between -750 and $1,000 \mathrm{mV}_{\mathrm{ECS}}$ at room temperature and between -650 and $-100 \mathrm{mV}_{\mathrm{ECS}}$ at $70^{\circ} \mathrm{C}$. At potentials higher than the pitting potential, a dramatic reduction in elongation was observed, in both temperatures. However, when the potential was held below $-650 \mathrm{mV}_{\mathrm{ECS}}$ at $70^{\circ} \mathrm{C}$ and $-750 \mathrm{mV}_{\mathrm{ECS}}$ at room temperature, a reduction in maximum elongation until rupture was observed, probably through hydrogen embrittlement mechanism.

Key words: Dúplex stainless steel; Stress corrosion cracking; Slow strain rate testing.

\footnotetext{
Estudante de Engenharia Metalúrgica, Universidade Federal do Rio Grande do Sul (UFRGS), Porto Alegre, RS, Brasil.

Engenheiro Metalúrgico, UFRGS, Porto Alegre, RS, Brasil.

Mestre em Engenharia, UFRGS, Porto Alegre, RS, Brasil.

Doutor em Engenharia, UFRGS, Porto Alegre, RS, Brasil.

Professora Doutora UFRGS, Porto Alegre, RS, Brasil.
}

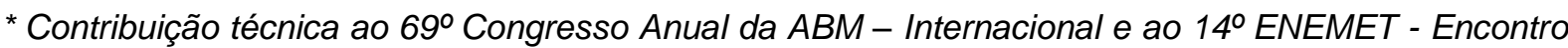
Nacional de Estudantes de Engenharia Metalúrgica, de Materiais e de Minas, 21 a 25 de julho de 2014, São Paulo, SP, Brasil.
} 


\section{INTRODUÇÃO}

Os aços inoxidáveis dúplex têm essa designação devido a sua microestrutura ser constituída de duas fases, ferrita $(\alpha)$ e austenita $(\gamma)$ [1]. O equilíbrio entre as fases é obtido principalmente pelo ajuste da composição química do cromo (Cr), níquel (Ni) e pelos tratamentos térmicos adequados [2].

Desde 1970, muitos estudos têm sido dedicados ao desenvolvimento e aprimoramento de processos de produção desse tipo de liga, bem como em pesquisas na área de corrosão. Como resultados os aços inoxidáveis dúplex estão hoje sendo empregados em uma ampla gama de aplicações como material estrutural em vários setores industriais, entre eles, na produção de petróleo em plataformas off shore $[3,4]$.

$\mathrm{O}$ alto teor de $\mathrm{Cr}$ e molibdênio (Mo) em conjunto com o nitrogênio, dão origem a uma elevada resistência à corrosão por pites em soluções contendo cloretos.

Os aços inoxidáveis dúplex também possuem uma maior resistência à corrosão sob tensão (CST) comparado aos aços inoxidáveis austeníticos [5].

A susceptibilidade dos aços inoxidáveis dúplex na CST tem sido estudada recentemente. Laitinen e Hanninen [6] investigaram a CST do dúplex UNS S31803 em solução contendo $50 \%$ em massa de $\mathrm{CaCl}_{2}$ em $100^{\circ} \mathrm{C}$. Eles observaram que 0 crescimento das trincas foram principalmente através da fase austenítica. Pelo contrário, Jargelius et al. [7], concluíram que em vez da ferrita, a austenita foi a fase que impediu a propagação da trinca, em várias soluções contendo cloreto, aquecidas até a temperatura de ebulição, 43,5\% $\mathrm{MgCl}_{2}, 63 \% \mathrm{CaCl}_{2}$ e $50 \%$ de $\mathrm{LiCl}$. Estas informações indicam que existem algumas controvérsias quanto ao efeito da microestrutura sobre os mecanismos da CST dos aços inoxidáveis dúplex, denotando assim, a necessidade de mais estudos sobre o comportamento desta liga em sistemas sob tais circunstâncias.

Além disso, a iniciação de uma trinca favorecida pela CST em meio contendo cloreto pode estar associada aos mecanismos de corrosão por pites ou dissolução seletiva de fases [6-8].

Uma das formas de proteção contra corrosão geralmente utilizada é a proteção catódica. Entretanto quando estes potenciais aplicados se encontram muito abaixo do potencial de corrosão do aço, a produção de hidrogênio pode ser considerável. Os aços inoxidáveis dúplex são considerados resistentes à fragilização por hidrogênio devido à estrutura dúplex com a austenita dúctil agindo no sentido de impedir a propagação da trinca nesse aço a partir da fase ferrítica, que por sua vez, é mais susceptível à fragilização por hidrogênio, devido à difusão preferencial do $\mathrm{H}$ em sua rede cristalina [9].

Segundo Shreir et al. [10], a resistência a ruptura, pela propagação de trincas geradas por CST, nos aços inoxidáveis dúplex varia com a temperatura, sendo menor na faixa dos $60-90^{\circ} \mathrm{C}$ do que a temperatura ambiente. O mecanismo detalhado de nucleação das trincas é complexo, pois envolve interações entre as diferentes respostas mecânicas e eletroquímicas das fases ferrita e austenita.

Este trabalho tem a intenção de avaliar a influência da temperatura sobre a resistência à corrosão sob tensão do aço inoxidável dúplex AISI 318 em solução contendo íons cloreto, saturada com $\mathrm{CO}_{2}$ através da técnica de baixa taxa de deformação. Além de estudar o efeito da temperatura sobre o mecanismo de CST desses aços, será estudado também o efeito do potencial aplicado, empregando potenciais anódicos e catódicos nos ensaios, avaliando a influência dos mesmos sobre a susceptibilidade à corrosão sob tensão da liga estudada.

\footnotetext{
* Contribuição técnica ao $69^{\circ}$ Congresso Anual da ABM - Internacional e ao 14ํㅡㄹ ENEMET - Encontro Nacional de Estudantes de Engenharia Metalúrgica, de Materiais e de Minas, 21 a 25 de julho de 2014, São Paulo, SP, Brasil.
} 


\section{MATERIAIS E MÉTODOS}

O material utilizado neste estudo foi o aço inoxidável dúplex AISI 318 com composição química mostrada na tabela 1. Esse material passou pelo processo de laminação até adquirir o formato de barras de $1000 \mathrm{~mm}$ de comprimento por $16 \mathrm{~mm}$ de diâmetro, posteriormente sofreu tratamento térmico de normalização. As microestruturas obtidas após tratamento térmico, nos cortes, longitudinal e transversal, podem ser observadas na figura $1(\mathrm{a})$ e (b), respectivamente.

Tabela 1. Composição química do aço inoxidável dúplex AISI 318, realizada por espectrometria de emissão atômica.

\begin{tabular}{c|c|c|c|c|c|c|c|c|c|c}
\hline Elemento & $\mathbf{C}$ & $\mathbf{S i}$ & $\mathbf{M n}$ & $\mathbf{N i}$ & $\mathbf{C r}$ & $\mathbf{M o}$ & $\mathbf{N}$ & $\mathbf{S}$ & $\mathbf{P}$ & $\mathbf{N b}$ \\
\hline $\begin{array}{c}\text { Percentual } \\
\text { em massa (\%) }\end{array}$ & 0,02 & 0,43 & 1,51 & 5,43 & 22,76 & 2,81 & 0,157 & 0,0008 & 0,024 & 0,02 \\
\hline
\end{tabular}
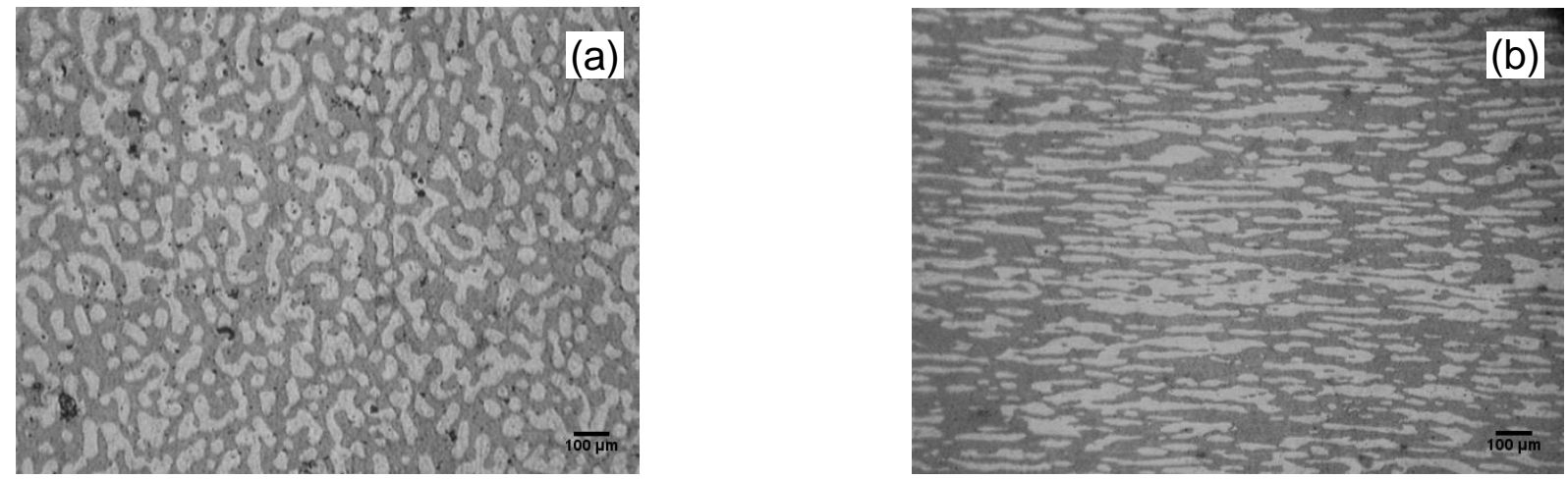

Figura 1. Micrografia em microscópio óptico do aço inoxidável dúplex AISI 318, microestruturas apresentadas após corte longitudinal (a), e transversal (b). Regiões claras e escuras representam as fases austenita e ferrita, respectivamente.

A solução aquosa empregada nos ensaios foi de $\mathrm{NaCl}$ contendo 115.000 ppm e pH 4 ajustado com a adição de ácido acético, saturada em $\mathrm{CO}_{2}$ durante todo o ensaio.

As curvas de polarização potenciodinâmicas foram obtidas com um potenciostato EG\&G Princeton Applied Research Modelo 273, com velocidade de varredura de potencial igual a $1 \mathrm{mV} / \mathrm{s}$. Utilizou-se uma célula eletroquímica composta de três eletrodos: eletrodo de referência de calomelano saturado (ECS), um contra eletrodo de platina e o corpo de prova (eletrodo de trabalho). Nas curvas de polarização realizadas a $70^{\circ} \mathrm{C}$ utilizou-se um banho termostático para o aquecimento da célula eletroquímica de dupla camisa. Os corpos de prova foram preparados com lixas de SiC até a granulometria 1000, montados em resina epóxi, conectados à parte traseira através de um fio de cobre. A determinação das curvas de polarização foram iniciadas com $50 \mathrm{mV}$ abaixo e acima do potencial de circuito aberto para as curvas anódicas e catódicas, respectivamente.

Nos ensaios de tração com baixa taxa de deformação, a velocidade utilizada foi de $1 \times 10^{-6} \mathrm{~s}^{-1}$, até a ruptura do corpo de prova. Os corpos de prova foram usinados segundo as regras da norma NACE TM0177-90 [11], conforme ilustrado na figura 2 , e lixados até a granulometria $600 \mathrm{com}$ a finalidade de remover as marcas de usinagem.

Foram realizados ensaios de tração com baixa taxa de deformação no meio corrosivo e ao ar, sem e com a aplicação de potenciais, em temperatura ambiente e

\footnotetext{
* Contribuição técnica ao $69^{\circ}$ Congresso Anual da ABM - Internacional e ao 14ํㅡㄹ ENEMET - Encontro Nacional de Estudantes de Engenharia Metalúrgica, de Materiais e de Minas, 21 a 25 de julho de 2014, São Paulo, SP, Brasil.
} 


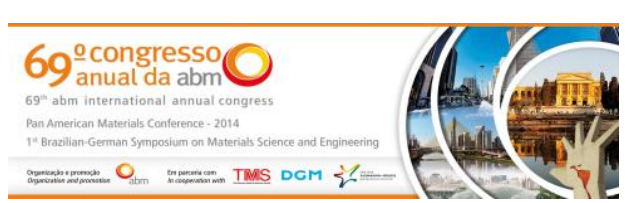

na temperatura de $70^{\circ} \mathrm{C}$. Utilizou-se óleo mineral neutro como meio para realização de um ensaio de tração na temperatura de $70^{\circ} \mathrm{C}$. Nos ensaios realizados a $70^{\circ} \mathrm{C}$ utilizou-se uma célula de dupla camisa composta de duas câmaras, sendo elas: interna, responsável por comportar o eletrólito e o corpo de prova e a câmara externa, por onde passa o fluxo de água aquecida, originada de um banho termostático com a finalidade de aquecer o eletrólito da câmara interna.

Para os ensaios de tração com baixa taxa de deformação com aplicação de potencial foram utilizados resultados das curvas de polarização como referência para escolha dos potenciais catódicos e anódicos a serem aplicados.

$\mathrm{Na}$ caracterização física das amostras, após ruptura dos corpos de prova, empregou-se um microscópio eletrônico de varredura Jeol, modelo JSM 5800, operando a $25 \mathrm{kV}$, um microscópio óptico Leica DMR e um microscópio estereoscópico modelo Optech-Bel Photonics SZT.

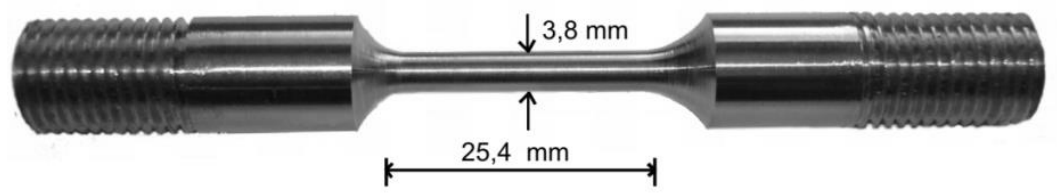

Figura 2. Dimensões dos corpos de prova utilizados nos ensaios de tração, segundo a norma NACE TM0177-90 [11].

\section{RESULTADOS E DISCUSSÃO}

\subsection{CURVAS DE POLARIZAÇÃO}

As curvas de polarização do aço dúplex nas temperaturas de $25^{\circ} \mathrm{C}$ e $70^{\circ} \mathrm{C}$ são observadas na figura 3. Nota-se grande influência da temperatura no comportamento à corrosão do aço inoxidável dúplex. Quando se passa de $20^{\circ} \mathrm{C}$ para $70^{\circ} \mathrm{C}$ ocorre um aumento de aproximadamente 20 vezes no valor da densidade de corrente passiva, também observa-se uma redução significativa na zona de passivação na temperatura de $70^{\circ} \mathrm{C}$ em comparação à curva de polarização realizada na temperatura ambiente, além de baixar levemente 0 potencial de corrosão ( $\left.E_{\text {corr }}\right)$. O maior efeito, entretanto, é observado no potencial de pite (Epite), que cai aproximadamente de $950 \mathrm{mV} \mathrm{VCS}_{\mathrm{E}}$, a temperatura ambiente, para valores da ordem de $-150 \mathrm{mV}_{\mathrm{ECS}}$ a $70^{\circ} \mathrm{C}$, tornando esse material muito mais susceptível a corrosão sob tensão nessa temperatura, já que em muitos sistemas o pite funciona como um concentrador de tensões e um iniciador desse tipo de corrosão.

A tabela 2 apresenta os parâmetros de corrosão: potencial de corrosão, ( $E_{\text {corr }}$, densidade de corrente de corrosão, (I corr), pela extrapolação das retas de Tafel, e o potencial de pite (Epite) obtidos a partir da figura 3.

\footnotetext{
* Contribuição técnica ao $69^{\circ}$ Congresso Anual da ABM - Internacional e ao 14ํㅡㄹ ENEMET - Encontro Nacional de Estudantes de Engenharia Metalúrgica, de Materiais e de Minas, 21 a 25 de julho de 2014, São Paulo, SP, Brasil.
} 


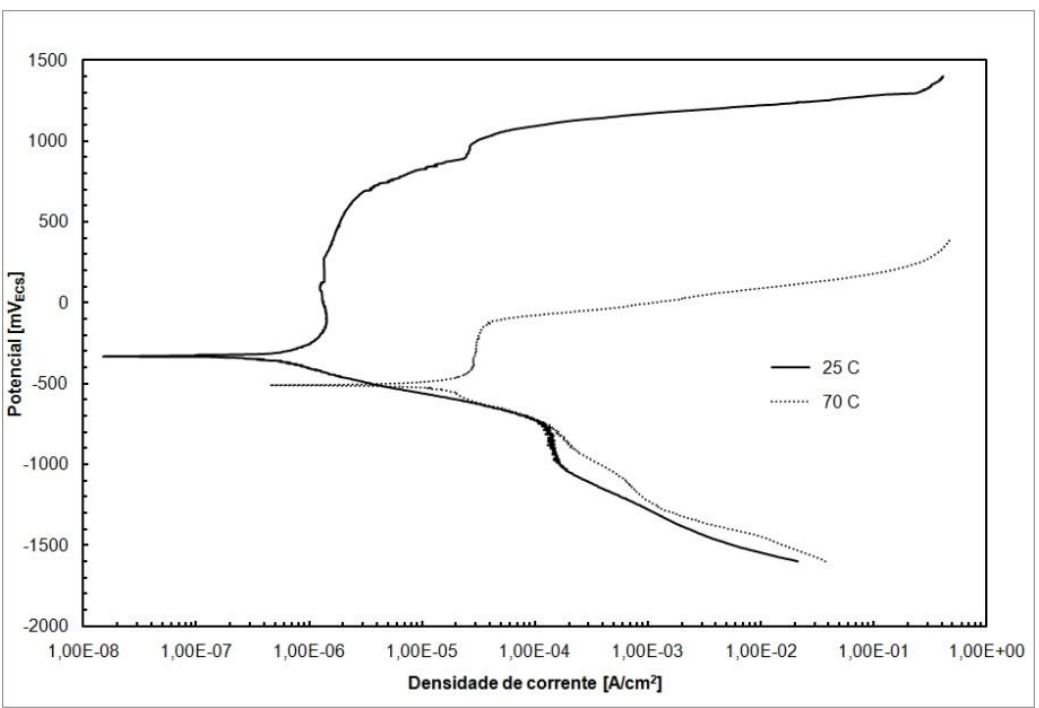

Figura 3. Curvas de polarização do aço inoxidável dúplex, AISI 318, realizadas em temperatura ambiente e a $70^{\circ} \mathrm{C}$.

Tabela 2. Valores dos parâmetros de corrosão obtidos através das curvas de polarização.

\begin{tabular}{cccc}
\hline Temperatura $\left({ }^{\circ} \mathrm{C}\right)$ & Ecorr $\left(\mathrm{mV}_{\mathrm{ECS}}\right)$ & Icorr $\left(\mathrm{A} / \mathrm{cm}^{2}\right)$ & Epite $\left(\mathrm{mV}_{\mathrm{ECS}}\right)$ \\
\hline 25 & -330 & $2,7 \times 10^{-7}$ & 950 \\
\hline 70 & -507 & $8,0 \times 10^{-6}$ & -150 \\
\hline
\end{tabular}

A figura 4 apresenta a imagem obtida através do microscópio estereoscópico, mostrando a superfície do corpo de prova contendo pites, após ser submetido ao ensaio potenciodinâmico a $70^{\circ} \mathrm{C}$.

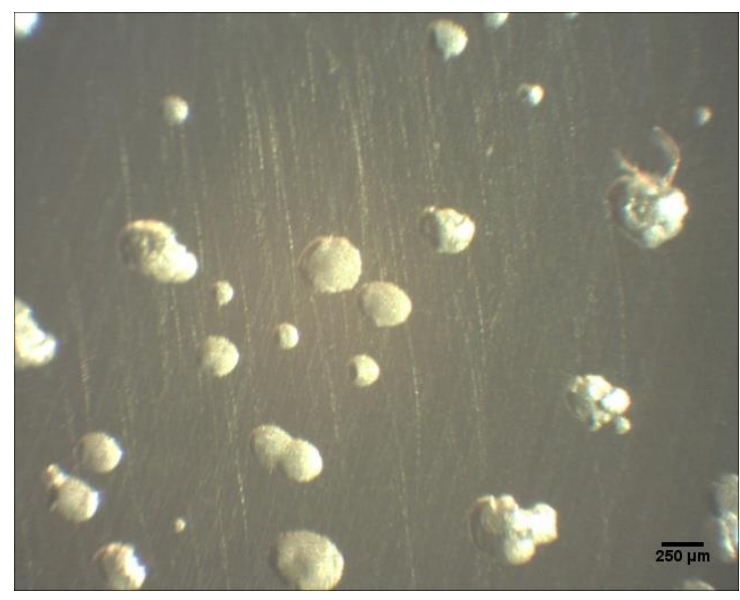

Figura 4. Morfologia em microscópio óptico dos pites formados no corpo de prova de aço inoxidável dúplex após ensaio potenciodinâmico a $70^{\circ} \mathrm{C}$.

\subsection{Ensaios de Baixa Taxa de Deformação}

\subsubsection{Potenciais catódicos}

O efeito da aplicação de potencias catódicos sobre o alongamento no ensaios de tração com baixa taxa de deformação na temperatura ambiente é demonstrado na figura 5 .

\footnotetext{
* Contribuição técnica ao 69ํ Congresso Anual da ABM - Internacional e ao 14ํㅡㄹ ENEMET - Encontro Nacional de Estudantes de Engenharia Metalúrgica, de Materiais e de Minas, 21 a 25 de julho de 2014, São Paulo, SP, Brasil.
} 

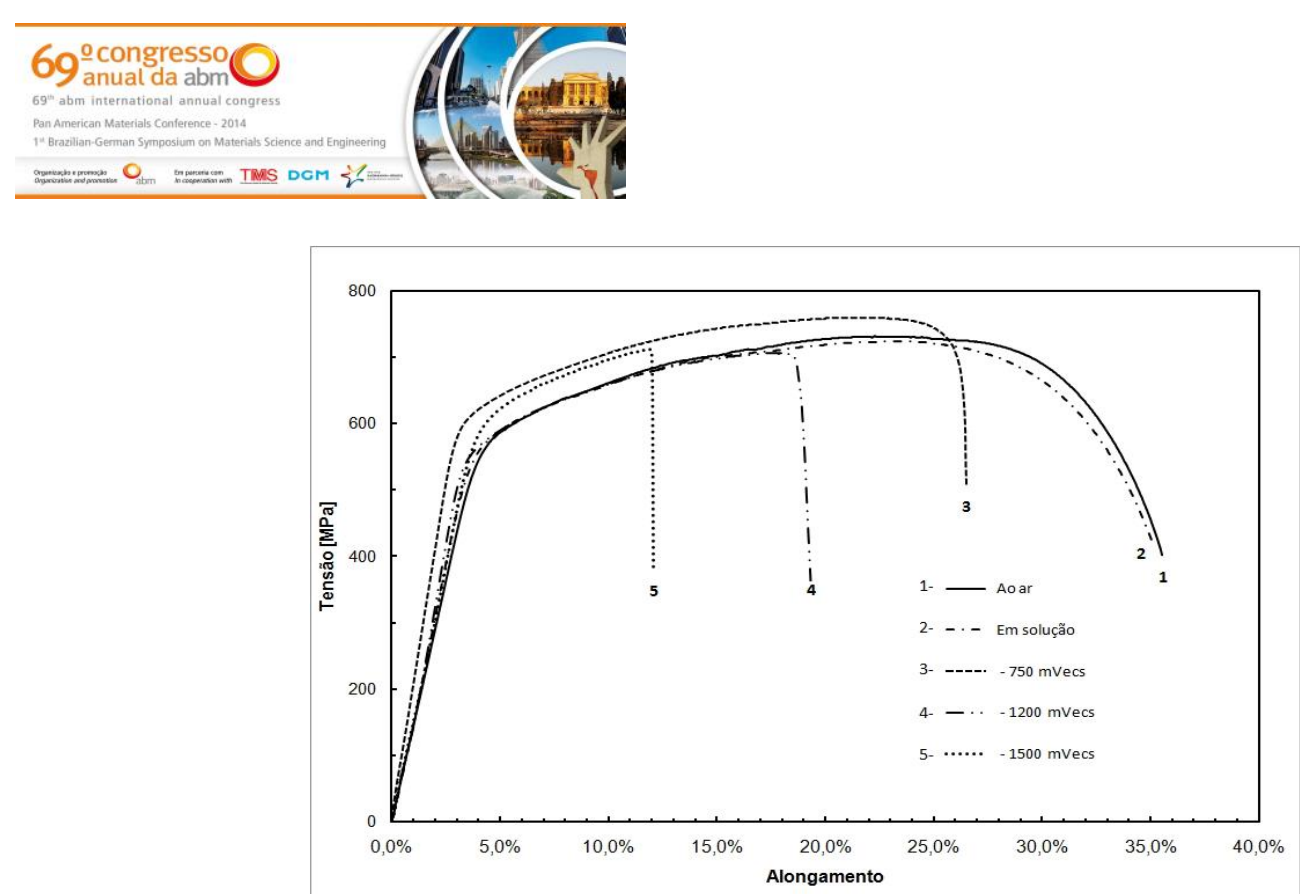

Figura 5. Efeito do potencial catódico aplicado nos ensaios de tração com baixa taxa de deformação do AISI 318, na temperatura ambiente, velocidade de $1 \times 10^{-6} \mathrm{~s}^{-1}$.

Os resultados, observados na figura 5, indicam uma grande influência do potencial aplicado sobre o alongamento total do aço registrado. Observa-se que, quanto menor (mais negativo) o potencial aplicado, menor o alongamento total do corpo de prova. Provavelmente a fase ferrita, que é susceptível a fragilização por hidrogênio, esteja comprometendo a integridade de todo o aço.

Resultados semelhantes são observados na figura 6 , onde também observa-se os ensaios de tração com baixa taxa de deformação com aplicação de potencias catódicos, mas realizados na temperatura de $70^{\circ} \mathrm{C}$.

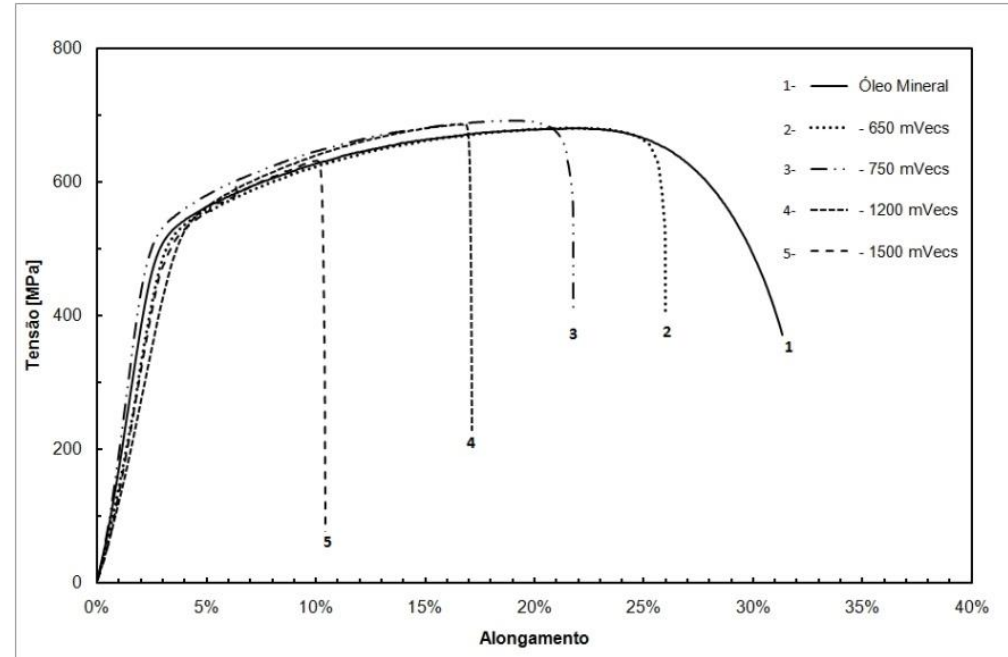

Figura 6. Efeito do potencial catódico aplicado nos ensaios de tração com baixa taxa de deformação do AISI 318 , na temperatura de $70^{\circ} \mathrm{C}$, velocidade de $1 \times 10^{-6} \mathrm{~s}^{-1}$.

Nos ensaios mostrados na figura 6 , na temperatura de $70^{\circ} \mathrm{C}$, em comparação aos resultados da figura 5, na temperatura ambiente, em potenciais equivalentes, podemos observar uma redução no alongamento máximo perseptível em todos os potenciais com o aumento da temperatura. Pode-se supor que este efeito esteja relacionado a um aumento na velocidade de difusão do hidrogênio na rede cristalina do aço.

\footnotetext{
* Contribuição técnica ao 69ํ Congresso Anual da ABM - Internacional e ao 14ํㅡㄹ ENEMET - Encontro Nacional de Estudantes de Engenharia Metalúrgica, de Materiais e de Minas, 21 a 25 de julho de 2014, São Paulo, SP, Brasil.
} 


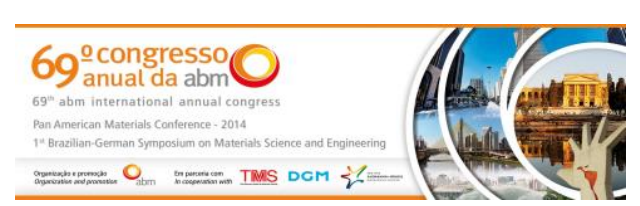

Tanto na temperatura ambiente como na temperatura de $70^{\circ} \mathrm{C}$, os ensaios de tração com baixa taxa de deformação com aplicação de potenciais catódicos, mostraram uma redução da extricção em função dos potenciais aplicados, como pode-se observar na figura 7, que ilustra as macrografias das fraturas dos corpos de prova utilizados nos ensaios de de tração com baixa taxa de deformação com aplicação de potenciais catódicos na temperatura de $70^{\circ} \mathrm{C}$. Também foram observadas, através do microscópio óptico, a presença de microtrincas na superfície dos corpos de prova perpendiculares a direção do carregamento, resultantes da fragilização do aço, provenientes de ensaios de tração com aplicação de potenciais catódicos, como podemos visualizar na figura $8 \mathrm{a}$ e na figura $8 \mathrm{~b}$, correspondentes às micrografias dos corpos de prova remanescentes dos ensaios de tração realizados a temperatura ambiente com aplicação de potencial catódico de $-1,5 \mathrm{~V}_{\mathrm{ECS}}$. Essas microtrincas parecem atravessar indistintamente as duas fases que compõe o aço.

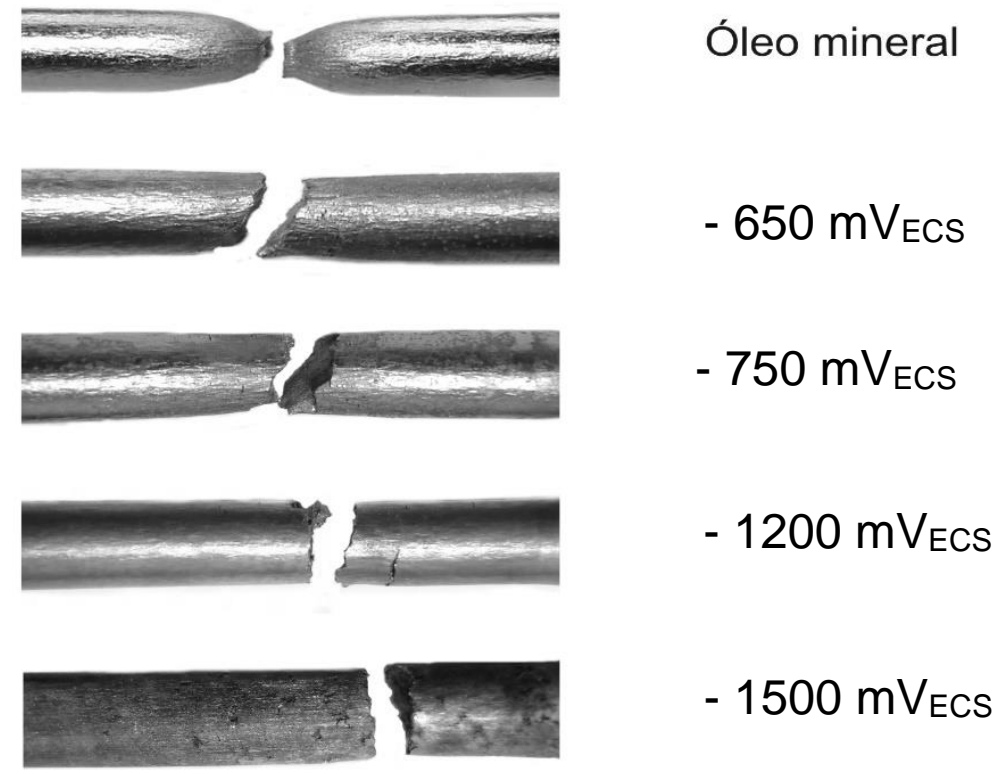

Figura 7. Macrografias das fraturas dos corpos de prova do AISI 318 após ensaio de tração com baixa taxa de deformação com aplicação de diferentes potenciais catódicos na temperatura de $70^{\circ} \mathrm{C}$.
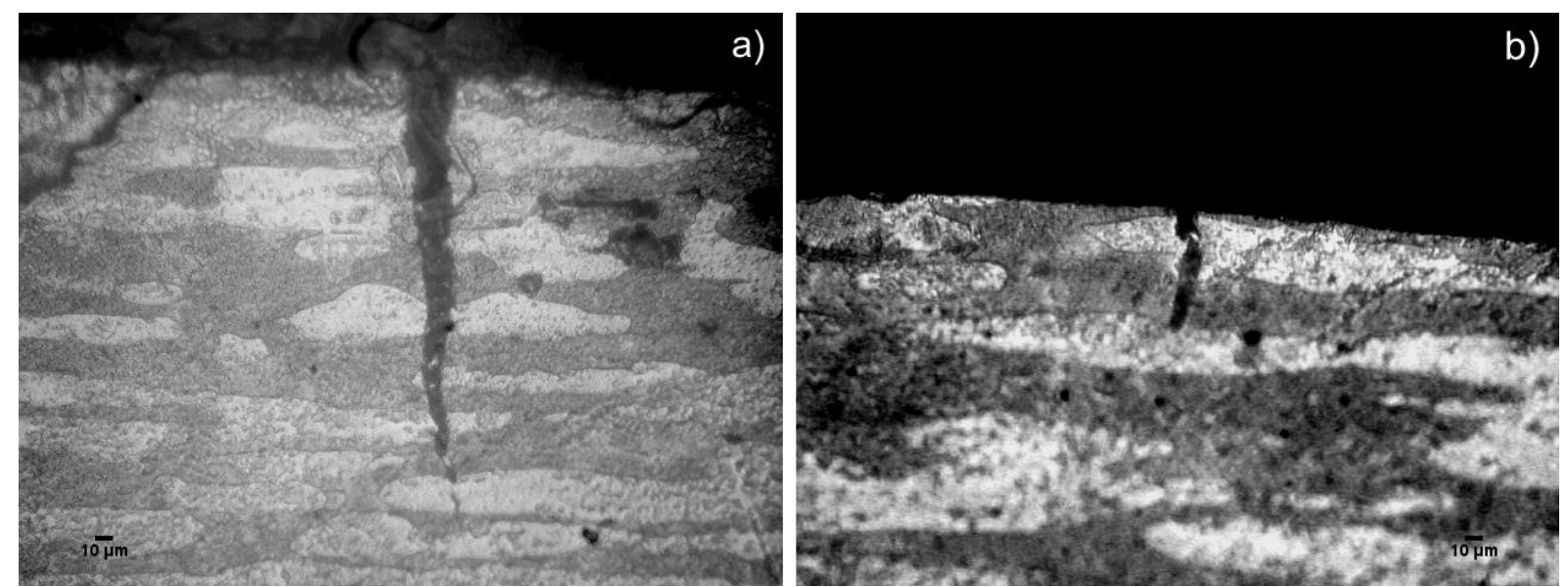

Figura 8. Micrografias em microscópio óptico evidenciando a presença de microtrincas no corpo de prova de aço inoxidável dúplex após ensaio de tração a temperatura ambiente, com aplicação de potencial de $-1,5 \mathrm{~V}_{\mathrm{ECS}}$.

\footnotetext{
* Contribuição técnica ao $69^{\circ}$ Congresso Anual da ABM - Internacional e ao 14ํㅡㄹ ENEMET - Encontro Nacional de Estudantes de Engenharia Metalúrgica, de Materiais e de Minas, 21 a 25 de julho de 2014, São Paulo, SP, Brasil.
} 


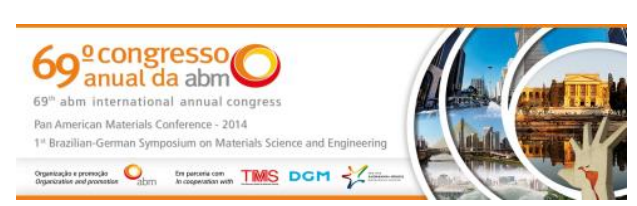

\subsubsection{Potenciais anódicos}

Ensaios de tração com baixa taxa de deformação e com aplicação de potenciais anódicos foram realizados nas temperaturas de 25 e $70^{\circ} \mathrm{C}$. Os resultados podem ser observados nas figuras 9 e 10, respectivamente.

A influência do potencial anódico aplicado nos ensaios de tração à baixa taxa de deformação, em ambas as temperaturas, 25 e $70^{\circ} \mathrm{C}$, somente são observados nos potenciais iguais ou superiores ao de pite. Observando-se as curvas de polarização do aço dúplex , para a temperatura ambiente e $70^{\circ} \mathrm{C}$, verifica-se que o potencial de pite, como já mencionado anteriormente, diminui consideravelmente quando se passa de de $25^{\circ} \mathrm{C}$ para $70^{\circ} \mathrm{C}$, tornando essa temperatura, de $70^{\circ} \mathrm{C}$, bem mais perigosa em termos de fragilização, já que o potencial de pite a $70^{\circ} \mathrm{C}$ se encontra muito proximo do potencial de corrosão. $O$ mesmo não é observado na curva de polarização realizada em $25^{\circ} \mathrm{C}$.

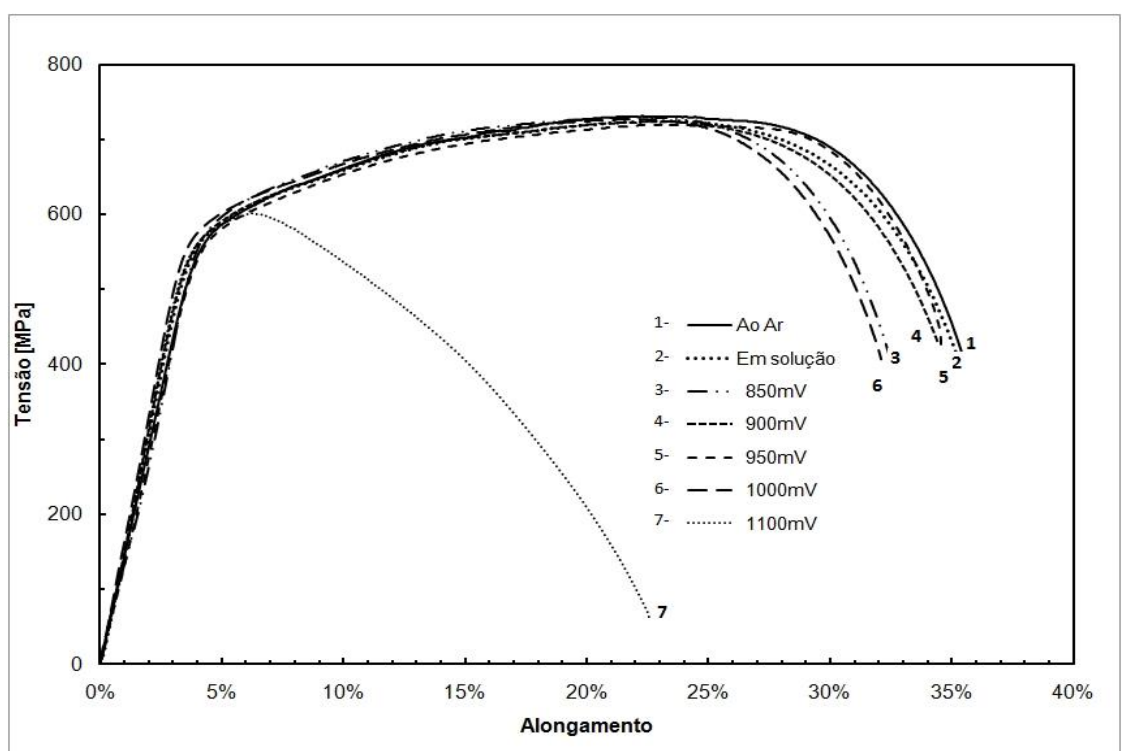

Figura 9. Efeito do potencial anódico aplicado nos ensaios de tração com baixa taxa de deformação do AISI 318 , na temperatura de $25^{\circ} \mathrm{C}$, velocidade de $1 \times 10^{-6} \mathrm{~s}^{-1}$.

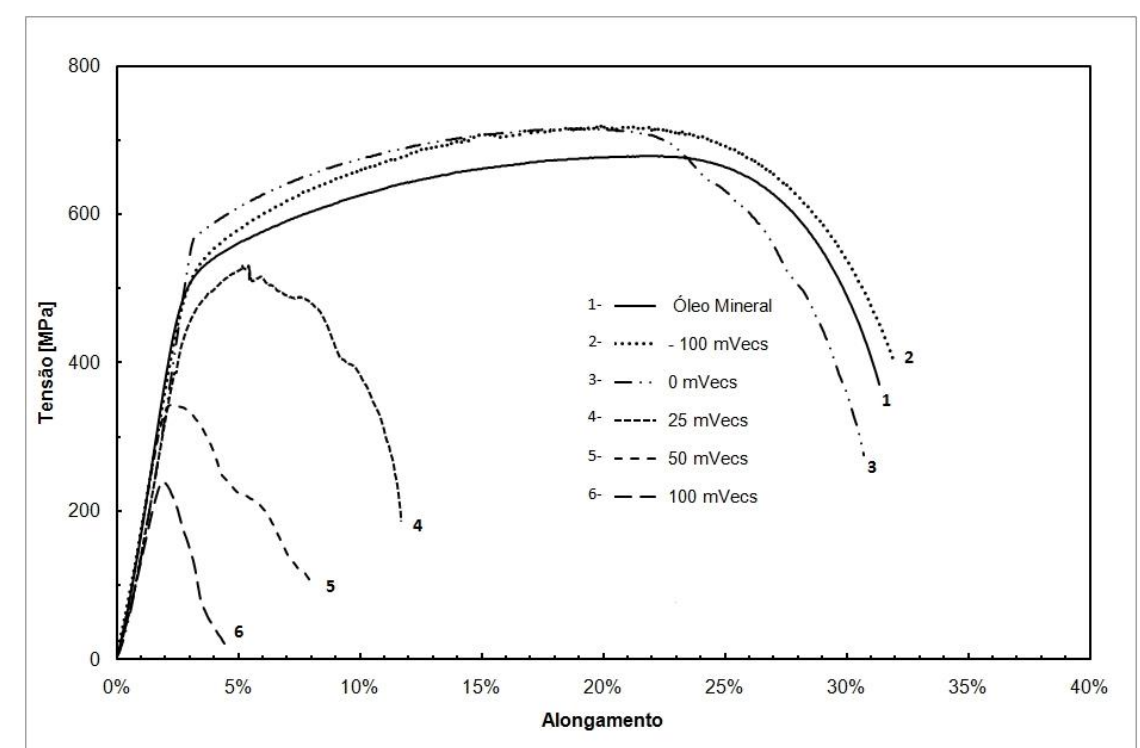

Figura 10. Efeito do potencial anódico aplicado nos ensaios de tração com baixa taxa de deformação do AISI 318 , na temperatura de $70^{\circ} \mathrm{C}$, velocidade de $1 \times 10^{-6} \mathrm{~s}^{-1}$.

* Contribuição técnica ao 69 Congresso Anual da ABM - Internacional e ao 14ํㅡㄹ ENEMET - Encontro Nacional de Estudantes de Engenharia Metalúrgica, de Materiais e de Minas, 21 a 25 de julho de 2014, São Paulo, SP, Brasil. 


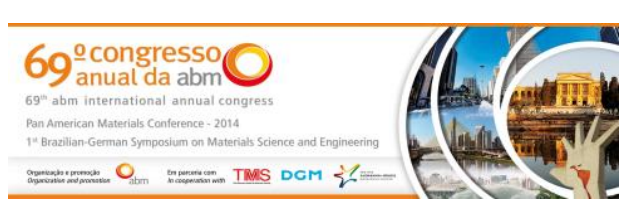

As reduções nos alongamentos máximos observados nos potenciais anódicos superiores ao potencial de pite, tanto na temperatura ambiente como em $70^{\circ} \mathrm{C}$ parecem estar relacionados apenas à dissolução do aço, conforme podemos observar na figura 11, que exibe o aspecto das rupturas dos corpos de prova após ensaio de tração com baixa taxa de deformação e com a aplicação de diversos potenciais anódicos na temperatura de $70^{\circ} \mathrm{C}$. No entanto, fissuras podem nuclear nessas irregularidades originadas na dissolução anódica, mesmo que não tenham sido observadas nesse trabalho.

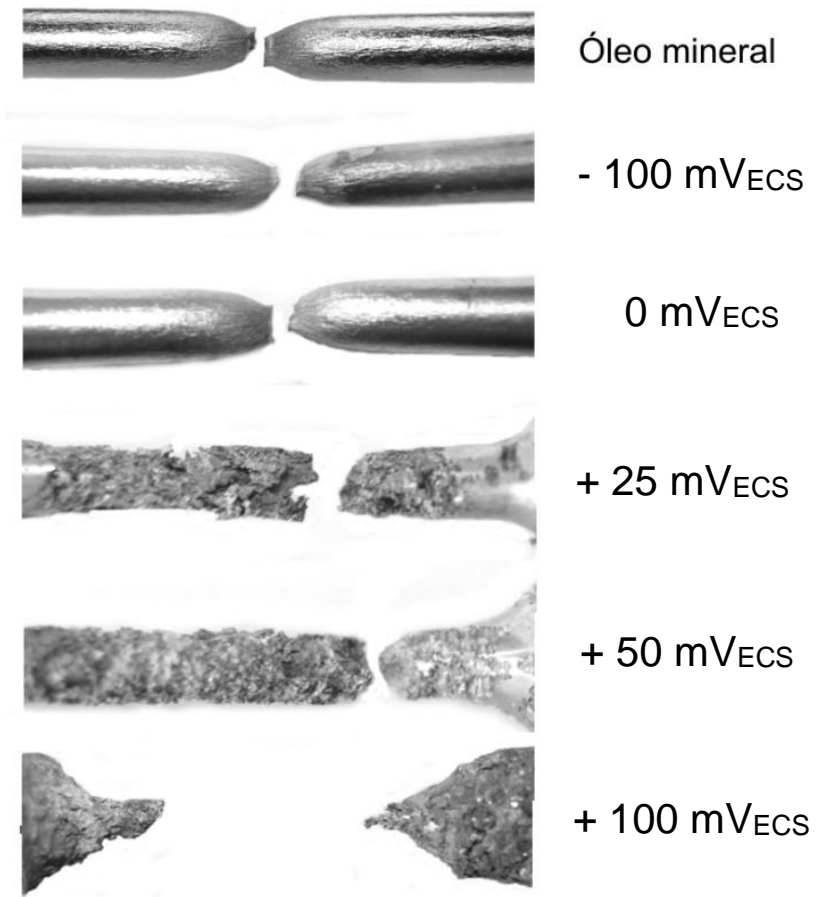

Figura 11. Macrografias das fraturas dos corpos de provas do AISI 318 após ensaio de tração com baixa taxa de deformação com aplicação de diferentes potenciais anódicos na temperatura de $70^{\circ} \mathrm{C}$.

As reduções nos alongamentos máximos observados nos potenciais anódicos superiores ao potencial de pite, tanto na temperatura ambiente como em $70^{\circ} \mathrm{C}$ parecem estar relacionados apenas à dissolução do aço.

\subsubsection{Microscopia eletrônica}

A redução acentuada da ductilidade é o principal efeito resultante da interação causada pelo hidrogênio na rede cristalina dos aços susceptíveis a essa fragilização. A fratura comumente encontrada nesses casos apresenta pouca ou nenhuma deformação plástica, ocorrendo de forma abrupta. A figura 12, itens (a), (b) e (c), apresentam as micrografias das regiões das fraturas dos corpos de prova submetidos à tração ao ar, com aplicação de potencial anódico (850mV $\mathrm{ECS}_{\text {) }}$, e com a aplicação de potencial catódico $\left(-1,1 \mathrm{~V}_{\mathrm{ECS}}\right)$, respectivamente.

\footnotetext{
* Contribuição técnica ao 69ำ Congresso Anual da ABM - Internacional e ao 14ํㅡㄹ ENEMET - Encontro Nacional de Estudantes de Engenharia Metalúrgica, de Materiais e de Minas, 21 a 25 de julho de 2014, São Paulo, SP, Brasil.
} 

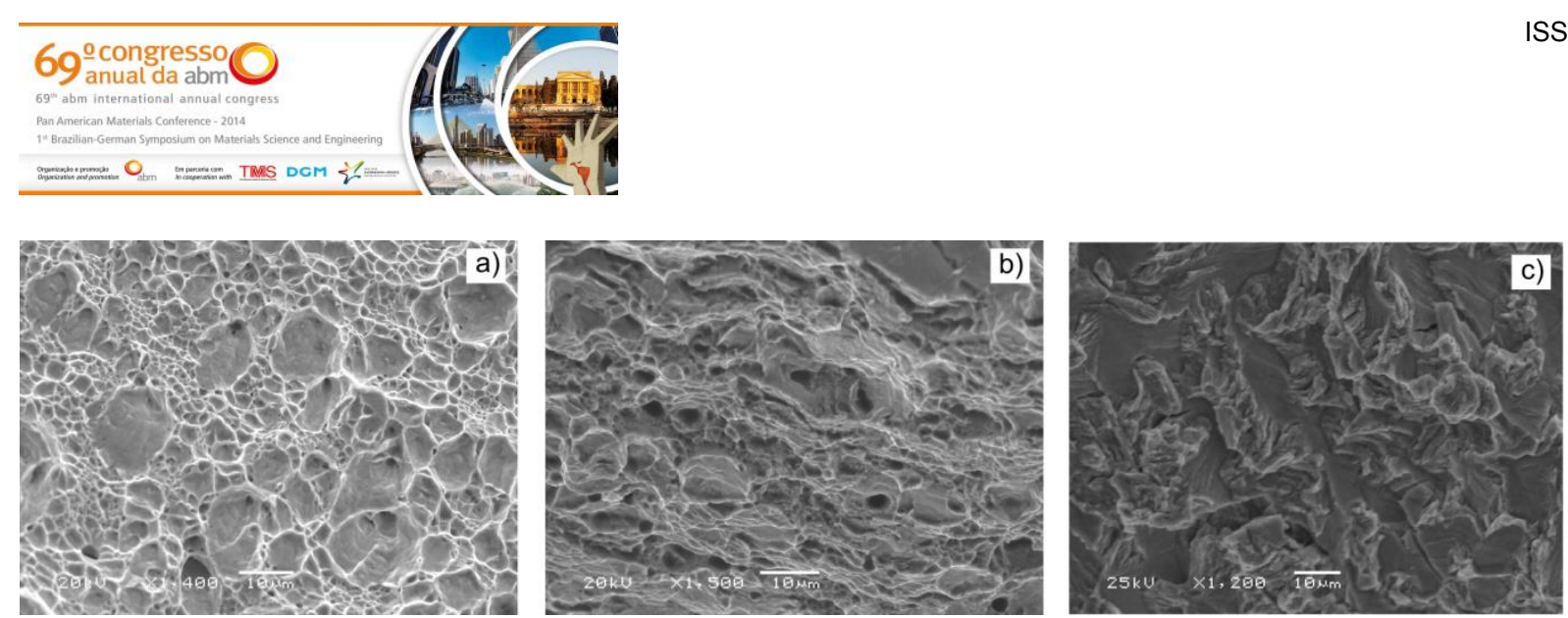

Figura 12. Imagem em MEV das regiões da fratura dos corpos de prova do AISI 318 após ensaio de tração com baixa taxa de deformação, realizado na temperatura ambiente. (a) ensaio ao ar, (b) em solução com aplicação de potencial anódico de $850 \mathrm{mV}_{\mathrm{ECS}}$, (c) em solução com aplicação de potencial catódico de $-1100 \mathrm{mV}$ ECS.

No itens (a) e (b) da figura 12 pode-se observar a presença de dimples, caracterizando que a fratura ocorreu de forma dúctil, do tipo taça cone com grande extricção. Entretanto, no item (c) da figura 12, observa-se na fratura planos de clivagem, caracterizando uma fratura do tipo frágil, provavelmente proveniente da fragilização por hidrogênio.

O aço inoxidável dúplex apresentou, através das curvas de polarização, uma excelente resistência à corrosão em solução contendo 115.000 ppm de íons cloreto, $\mathrm{pH} 4$ e $\mathrm{CO}_{2}$, na temperatura ambiente, além de possuir um elevado potencial de pite em comparação aos aços inoxidáveis austeníticos, como apresentaram Senatore M et al [12], no estudo onde compararam, entre outras propriedades, a resistência à corrosão dos aços inoxidáveis dúplex e os tradicionais aços inoxidáveis austeníticos AISI 304L e 316L.

Contudo, na temperatura de $70^{\circ} \mathrm{C}$, o mesmo aço não obteve o mesmo comportamento. A curva de polarização realizada nessa temperatura, mostrou um considerável decréscimo no potencial de pite, além da elevação da densidade de corrente de passivação do material.

Os resultados dos ensaios de tração à baixa taxa de deformação, em ambas temperaturas $\left(25\right.$ e $\left.70^{\circ} \mathrm{C}\right)$, indicaram uma imunidade à corrosão sob tensão presente em uma grande amplitude de potenciais, que compreende a zona de passivação anódica até potenciais catódicos da ordem de aproximadamente - $600 \mathrm{mV}$ ECS .

Tsai e Chou[13], investigaram o efeito da aplicação de potenciais catódicos no aço inoxidável dúplex em solução constituída de $26 \%$ em peso de $\mathrm{NaCl}$ e $\mathrm{pH} 2$. Atravésde ensaios com baixa taxa de deformação Tsai e Chou [13] concluíram que, para o sistema em estudo, o aço inoxidável dúplex apresentou imunidade entre o potencial de circuito aberto e - $245 \mathrm{mV} \mathrm{ECS}_{\mathrm{E}}$, além de uma redução no alongamento do corpo de prova para potenciais menores ou iguais a - $380 \mathrm{mV} \mathrm{ECS}_{\text {. Ainda sobre } \mathrm{o}}$ estudo de Tsai e Chou [13], esses autores observaram a propagação de microtrincas secundárias abaixo da região da fratura nos corpos de prova após ensaio de tração com aplicação de potencial catódico de $-1500 \mathrm{mVECS}$, semelhantes às apresentadas neste trabalho, como pode-se verificar na figura 8. Porém nas micrografias de Tsai e Chou [13], fica evidente que a propagação das fissuras ocorre principalmente na fase ferrita, confirmando a susceptibilidade da fase ferrita à fragilização por hidrogênio [9]. Em outras palavras, a não constatação nesse trabalho da propagação preferencial de trincas na fase ferrita não indica que a mesma não ocorra.

Comparando-se os resultados dos ensaios de tração com aplicação de potenciais catódicos a temperatura ambiente, com os equivalentes à temperatura de $70^{\circ} \mathrm{C}$,

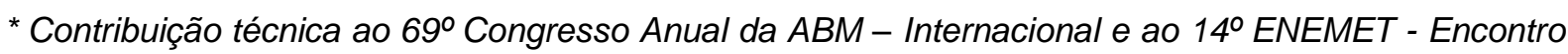
Nacional de Estudantes de Engenharia Metalúrgica, de Materiais e de Minas, 21 a 25 de julho de 2014, São Paulo, SP, Brasil.
} 


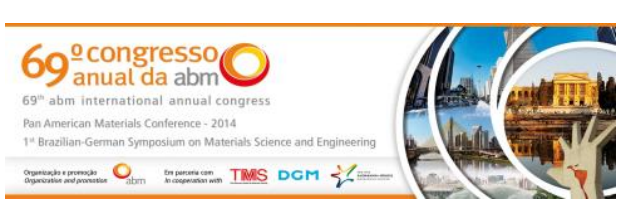

pela presença de microtrincas geradas, provavelmente, por um processo de fragilização pelo hidrogênio.

\section{Agradecimentos}

À CAPES e ao CNPq pelo apoio financeiro.

\section{REFERÊNCIAS}

1 Charles J. Why and where dúplex stainless steels. In: PROC. 5TH Dúplex Stainless Steel Conference, 1997, Maastricht, Netherlands. p. 29-42.

2 Josefsson B, Nelsson J, Wilson A. Phase Transformations in Dúplex Steels and the Relation Between Continuous Cooling and Isothermal Heat Treatment. In: Proceedings Of The Dúplex Stainless Steel Conference, 1991, Beaune, France. p. 67-78.

3 Gunn RN. Dúplex Stainless Steels: Microstructure, properties and applications. Cambridge: Abington Publishing, 1997.

4 Davison RM, Redmond JD. Practical guide to using dúplex stainless steels. Materials Performance. jan. 1990. p. 57-62.

5 Hutchings RB, Turnbull A, May AT. Measurement of Hydrogen Transport in a Dúplex Stainless Steel. Scripta Metallurgica et Materialia, 1991; 25(12): 2657-2662.

6 Laitinen A, Hanninen H. Chloride-Induced Stress Corrosion Cracking of Powder Metallurgy Dúplex Stainless Steels. Corrosion, 1996; 4: 295-306.

7 Jargelius RFA, Blom R, Hertzman S, Linder J. Dúplex stainless steel '91, in: J. Charles, S. Bernhardson (Ed.). Les Editions de Physique I. p.211, 1992.

8 Miyasaka A, Kanamaru T, Ogawa H. Critical Stress for Stress Corrosion Cracking of Dúplex Stainless Steel in Sour Environments. Corrosion, 1996; 52(8): 592-599.

9 Zakroczymski T, Owzcarek E. Electrochemical investigation of hydrogen absorption in a dúplex stainless steel. Acta Materialia, 2002; 50(10): 2701-2713.

10 Shreir LL. et al. Corrosion: Metal/environmental reactions. 3.ed. Oxford: ButterworthHeinemann, v. 1, 1994.

11 National Association of Corrosion Engineers. TM0177-90, n. 53040: Standart Test Method. Houston, 1990. 22 p.

12 Senatore M, Finzetto L, Perea E. Estudo comparativo entre os aços inoxidáveis dúplex e os inoxidáveis AISI 304L/316L. Revista da Escola de Minas, Ouro Preto, 2007; 60(1).

13 Tsai WT, Chou SL. Environmentally assisted cracking behavior of dúplex stainless steel in concentrated sodium chloride solution. Corrosion Science, Oxford, 2000; 42(10): 1741-1762.

14 Schroeder RM. Comportamento eletroquímico e susceptibilidade à corrosão sob tensão do aço ABNT 1080 utilizado em armaduras de concreto protendido. PPGEM, Universidade Federal do Rio Grande do Sul, Porto Alegre, 1999.

15 Tsai WT, Chen MS. Stress corrosion cracking behavior of 2205 dúplex stainless steel in concentrated $\mathrm{NaCl}$ solution. Corrosion Science, Oxford, 2000; 42(3): 545-559.

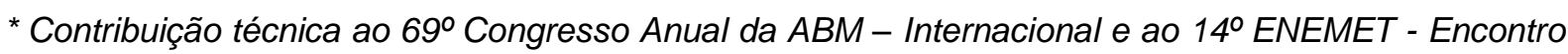
Nacional de Estudantes de Engenharia Metalúrgica, de Materiais e de Minas, 21 a 25 de julho de 2014, São Paulo, SP, Brasil.
} 